2016-06-01

\title{
Wave energy in Europe: Views on experiences and progress to date
}

\section{O'Hagan, AM}

http://hdl.handle.net/10026.1/4561

\subsection{6/j.jome.2015.09.001}

International Journal of Marine Energy

Elsevier BV

All content in PEARL is protected by copyright law. Author manuscripts are made available in accordance with publisher policies. Please cite only the published version using the details provided on the item record or document. In the absence of an open licence (e.g. Creative Commons), permissions for further reuse of content should be sought from the publisher or author. 


\title{
Wave energy in Europe: Views on experiences and progress to date
}

\author{
A.M. O'Hagan ${ }^{\text {a,* }}$, C. Huertas ${ }^{\text {b }}$, J. O'Callaghan ${ }^{\text {a }}$, D. Greaves ${ }^{\text {c }}$ \\ ${ }^{a}$ MaREI, Environmental Research Institute, University College Cork, Co. Cork, Ireland \\ ${ }^{\mathrm{b}}$ Abengoa Seapower, Campus Palmas Altas, C/Energía Solar $n^{\circ} 1$, Palmas Altas, Seville, Spain \\ ' School of Marine Science and Engineering, University of Plymouth, Marine Building, Drakes Circus, Plymouth PL4 8AA, \\ England, United Kingdom
}

\section{A R T I C L E I N F O}

\section{Article history:}

Received 15 October 2014

Revised 25 August 2015

Accepted 7 September 2015

Available online $\mathrm{xxxx}$

\section{Keywords:}

Wave energy

Consenting

Environment

Streamlining

Barriers

Accelerators

\begin{abstract}
A B S T R A C T
Through the Intelligent Energy Europe-funded SOWFIA project, the experiences of developers, regulators and stakeholders in relation to consenting wave energy deployments to date was assessed and analysed. The work focussed on wave energy test centres in Europe and involved consultation with wave energy device and project developers, regulatory authorities, stakeholders, environmental consultants and others through dedicated workshops and questionnaire surveys. Themes that arise in the analysis relate to planning and consenting processes, administrative procedures, Environmental Impact Assessment and stakeholder consultation. An analysis of the barriers as perceived by those consulted is presented and discussed, and recommendations are drawn from the analysis within each of the themes. In particular the need for Maritime Spatial Planning (MSP) to alleviate complex planning and consenting processes; the need for coordination of administrative procedures; the need for clearer requirements in the EIA process; and the need for early participation of stakeholders in consultation are discussed. Progress has been made in many EU countries but certain priority areas remain to be addressed if wave energy is to realise its full potential.
\end{abstract}

(c) 2015 Elsevier Ltd. All rights reserved.

* Corresponding author at: MaREI Centre, Beaufort Building - Environmental Research Institute (ERI), University College Cork, Haulbowline Road, Ringaskiddy, Co. Cork, Ireland. Tel.: +353214864325.

E-mail address: a.ohagan@ucc.ie (A.M. O’Hagan). 


\section{Introduction}

The wave energy industry is a new and developing industry which aims to contribute to the delivery of the EU's renewable energy targets whilst simultaneously supporting sustainable development in the EU's maritime sector and associated coastal communities [1]. As a pre-commercial industry, many technological and non-technological barriers exist, which can have the effect of inhibiting the development and further progress of the industry [2]. Technical barriers refer to those which require a technological solution and may include not only device-related aspects but also those surrounding cabling, vessels for deployment and data collection. In contrast, non-technical barriers are those factors that are not directly related to technology development but which can hinder deployment of wave energy devices. Common non-technical barriers are access to financial support, regulatory issues, potential environmental impacts and issues relating to social acceptance of development. Whilst the future success of wave energy will be dependent on technology convergence and efficient performance, the economic, environmental and social aspects of its development must also be resolved. To date, research findings on the non-technical barriers has tended to come from dedicated research projects and their outputs. Examples include the WAVEPLAM [2], EquiMar [3], ORECCA [4] and SOWFIA [5] projects, all of which identify consenting and environmental effects as two significant barriers to progress. There is a paucity of scientific literature pertaining to actual experiences of wave energy developments to date and how this experience can inform future planning and management approaches. This paper addresses these topics and is based on work carried out during the Streamlining of Ocean Wave Farm Impact Assessment (SOWFIA) project, funded by the EU's Intelligent Energy Europe programme administered by the EU's Executive Agency for Competitiveness and Innovation (EACI) [now EASME, the Executive Agency for Small and Medium-sized Enterprises].

Consenting processes and Environmental Impact Assessment (EIA) are commonly identified as two of the most significant non-technological barriers to be addressed by the wave energy industry. Currently wave energy devices tend to be deployed as single units either in dedicated test centres or independently in suitable locations. As the industry progresses, deployments will be in arrays of up to five device units and eventually in farms of multiple units, depending on the operating principle of the device. Accordingly planning and consenting process will need to be able to deal not only with this new maritime use but also to ensure the necessary consents are administered in a suitable, timely and transparent manner whilst also ensuring that environmental integrity is maintained and potential impacts minimised. In recent years, a number of EU Member States have had wave energy devices deployed in their adjoining waters. Experience has, therefore, been gained by wave energy developers, regulatory authorities and stakeholders in the maritime environment and surrounding communities. This paper presents these experiences along with perceptions of how the various aspects of consenting process are viewed with the aim of assessing whether consenting processes and EIA are still considered as barriers to the development of the wave energy industry. The paper culminates with a number of strategic and operational recommendations which could be implemented by all actors (regulators, developers and stakeholders) in an effort to streamline the process.

\section{Law and policy context}

Commitments at international level to cut greenhouse emissions and combat climate change have resulted in supranational organisations and national Governments developing and implementing ambitious climate change and energy policies. The European Union (EU) aims to get 20\% of its energy from renewable sources by 2020. This will have the effect of reducing reliance on imported energy whilst also encouraging technological innovation and increasing employment across EU Member States. The EU's Renewable Energy Directive (2009/28/EC) provides the legal framework for promoting renewable energy and also sets renewable energy targets for all Member States to achieve by 2020. The Directive required Member States to submit National Renewable Energy Action Plans (NREAPs) 
by June 2010. Article 13(1) of the Directive also requires the simplification of the administrative regimes faced by renewable energy, together with improvements to the electricity grid, to improve access for electricity from renewable energy.

Wave energy has the largest offshore renewable energy potential in Europe and worldwide and many different approaches to wave energy conversion have emerged. The Marine Institute and Sustainable Energy Ireland [6] state that "Europe's accessible wave power resource is calculated to be of the order of 320,000 MW with the highest resource available near the west of Ireland". A number of coastal Member States have included ocean energy targets within their published NREAPs. Generally, and specifically within the NREAPs, ocean energy is taken to include both wave and tidal energy. Offshore wind is treated independently. Publishing targets for ocean energy indicates not only the potential wave energy resource that exists in some Member States but could also be interpreted as signifying an aspiration to support ocean energy development. This is further evidenced by incentives, both financial and legal, and dedicated sectoral strategies adopted by some national governments, e.g. Ireland.

The ocean energy targets provide a scenario of the scale of development regulators will potentially be faced with in the EU up to 2020. For the majority of Member States with specified ocean energy targets, these will consist primarily of wave energy developments. This can be attributed to the fact that, apart from in the UK and France, the tidal resource in most Member States is not sufficient for commercial scale tidal energy developments. Table 1 presents an estimation of total contribution

Table 1

Estimation of total contribution (installed capacity, gross electricity generation) expected from ocean (wave and tidal) and offshore wind to meet the binding 2020 targets and the indicative interim trajectory for the shares of energy from renewable resources in electricity for 2010-2014.

\begin{tabular}{|c|c|c|c|c|c|c|c|}
\hline Member State & Source & $\begin{array}{l}2010 \\
(\mathrm{MW})\end{array}$ & $\begin{array}{l}2013 \\
\text { (MW) }\end{array}$ & $\begin{array}{l}2014 \\
(\mathrm{MW})\end{array}$ & $\begin{array}{l}2015 \\
(\mathrm{MW})\end{array}$ & $\begin{array}{l}2017 \\
(\mathrm{MW})\end{array}$ & $\begin{array}{l}2020 \\
(\mathrm{MW})\end{array}$ \\
\hline \multirow[t]{2}{*}{ Belgium [7] } & Tide, Wave, Ocean & $\mathrm{n} / \mathrm{a}$ & $\mathrm{n} / \mathrm{a}$ & $\mathrm{n} / \mathrm{a}$ & $\mathrm{n} / \mathrm{a}$ & $\mathrm{n} / \mathrm{a}$ & $\mathrm{n} / \mathrm{a}$ \\
\hline & Offshore wind & $\mathrm{n} / \mathrm{a}$ & $\mathrm{n} / \mathrm{a}$ & $\mathrm{n} / \mathrm{a}$ & $\mathrm{n} / \mathrm{a}$ & $\mathrm{n} / \mathrm{a}$ & $\mathrm{n} / \mathrm{a}$ \\
\hline \multirow[t]{2}{*}{ Denmark [8] } & Tide, Wave, Ocean & 0 & 0 & 0 & 0 & 0 & 0 \\
\hline & Offshore wind & 661 & 1256 & 1256 & 1251 & 1302 & 1339 \\
\hline \multirow{2}{*}{ France [9] } & Ocean current, wave, tidal & 240 & 271 & 287 & 302 & 333 & 380 \\
\hline & Offshore wind & 5542 & 8512 & 9572 & 2667 & 4000 & 6000 \\
\hline \multirow[t]{2}{*}{ Germany [10] } & Tide, Wave, Ocean & 0 & 0 & 0 & 0 & 0 & 0 \\
\hline & Offshore wind & 150 & 1302 & 2040 & 3000 & 5340 & 10,000 \\
\hline \multirow[t]{2}{*}{ Greece [11] } & Tide, Wave, Ocean & 0 & 0 & 0 & 0 & 0 & 0 \\
\hline & Offshore wind & 0 & 0 & 0 & 0 & 100 & 300 \\
\hline \multirow[t]{4}{*}{ Ireland $^{\mathrm{a}}[12]$} & Tide, Wave, Ocean (a) & 0 & 0 & 0 & 0 & 13 & 75 \\
\hline & (b) & 0 & 0 & 0 & 0 & 125 & 500 \\
\hline & Offshore wind (a) & 36 & 252 & 252 & 252 & 416 & 555 \\
\hline & (b) & 36 & 252 & 252 & 539 & 1352 & 2408 \\
\hline \multirow[t]{2}{*}{ Italy [13] } & Tide, Wave, Ocean & 0 & 0 & 0 & 0 & 1 & 3 \\
\hline & Offshore wind & 0 & 100 & 129 & 168 & 290 & 680 \\
\hline \multirow[t]{2}{*}{ Portugal [14] } & Tide, wave, ocean & 5 & 10 & 35 & 60 & 100 & 250 \\
\hline & Offshore wind & 0 & 0 & 0 & 25 & 25 & 75 \\
\hline \multirow[t]{2}{*}{ Spain [15] } & Tide, wave, ocean & 0 & 0 & 0 & 0 & 30 & 100 \\
\hline & Offshore wind & 0 & 0 & 50 & 150 & 1000 & 3000 \\
\hline \multirow[t]{2}{*}{ Sweden [16] } & Tide, wave and ocean energy & 0 & 0 & 0 & 0 & 0 & 0 \\
\hline & Offshore wind & 76 & 108 & 118 & 129 & 150 & 182 \\
\hline \multirow[t]{2}{*}{ The Netherlands [17] } & Tide, Wave, Ocean & 0 & 0 & 0 & 0 & 0 & 0 \\
\hline & Offshore wind & 228 & 465 & 940 & 1178 & 2778 & 5178 \\
\hline \multirow[t]{2}{*}{ United Kingdom [18] } & Tide, wave, ocean & 0 & 0 & 0 & 0 & 400 & 1300 \\
\hline & Offshore wind & 1390 & 3470 & 4450 & 5500 & 8310 & 12,990 \\
\hline
\end{tabular}

a Both a modelled and a non-modelled scenario are presented in the NREAP for Ireland. Figures (a) relate to the modelled scenario and figures (b) are from the non-modelled scenario. The non-modelled scenario is an 'export' scenario illustrating Ireland's potential to become a net exporter if the appropriate conditions (economic, technical and environmental) existed. It could be considered as aspirational. 
(installed capacity, gross electricity generation) expected from ocean (wave and tidal) and offshore wind to meet the binding Member State 2020 targets, in selected years from 2010 to 2020.

According to the European Renewable Energy Council [19], ocean energy will represent $0.15 \%$ of electricity consumption in 2020. The Council states that installed capacity is expected to increase from $245 \mathrm{MW}$ in 2010 to $2543 \mathrm{MW}$ in 2020 . It should be noted however that $240 \mathrm{MW}$ of that $245 \mathrm{MW}$ installed capacity can be solely attributed to the Rance tidal power station in France. The EREC Roadmap states that, overall, the NREAPs are "rather satisfying" with respect to ocean energy, considering that the main Member States active in the industry have set firm targets and thus reaffirmed their willingness to invest in and develop these new technologies [19]. The Roadmap highlights that Denmark is the only exception to this as it has not set a target for the ocean energy sector.

Other law and policy objectives can also influence the progress of wave energy. In the EU the recent Blue Growth strategy is notable as it seeks to capture the available potential of Europe's oceans, seas and coasts for jobs and growth with five key focus areas: blue energy; aquaculture; maritime, coastal and cruise tourism; marine mineral resources; and blue biotechnology [20]. Under blue energy, the Blue Growth strategy recognises that offshore wind could meet $4 \%$ of the EU's electricity demand by 2020 and $14 \%$ by 2030 translating into 170,000 jobs by 2020 , which would increase to 300,000 by 2030 [20, p.7]. Ocean energy is described as being at an early stage of development the challenge being "to accelerate the commercialisation of ocean energy through reductions in technology costs" [20, p.7]. To progress the Blue Growth agenda, the European Commission launched a public consultation on ocean energy in June 2012 which aimed at drawing together opinions and ideas on whether and how to help the sector move forward. The responses (128), therefore, provided a basis for an assessment of the policy options available to support this sector at the EU level. A follow-up Communication [21] was published in January 2014 and comprises a two-step action plan for development of the sector.

In the aforementioned consultation respondents were asked about barriers to development of ocean energy. Issues related to grid connection were the most frequently quoted barrier to the development of ocean energy overall, with $56 \%$ of respondents indicating that this is a problem [22]. The length and complexity of the consenting process and associated procedures were highlighted by $55 \%$ respondents as the most prominent administrative barriers. This was followed by a lack of qualified staff (26\% respondents) and the length and complexity of licensing across borders (27\% respondents). Other barriers within this category include the number of regulators involved in the consenting process, issues surrounding the interpretation of other EU legal instruments and the requirements of the EIA process [22]. Developments at sea require consent in much the same way as developments on land. Given the complexity of maritime developments however, there are often a range of consents, licences and permissions to be obtained before construction and operation can occur. These administrative procedures tend to be governed by national legislation but must take into account over-arching legal requirements of the EU such as Environmental Impact Assessment and Public Participation.

\section{Progress to date}

At the time of writing, only limited progress has been made in reaching the ocean energy targets. There are a number of possible explanations for this, ranging from technology readiness to financial support and the global economic climate. More than 50 types of wave energy converters have been designed, but less than $20 \%$ have reached full scale prototype stage [23]. Currently wave energy device deployments across Europe tend to be of a short-term nature and comprised of medium to full scale devices. The aim of these deployments has been to test or demonstrate different device types and components. Most deployments have taken place at wave energy test centres, established in different Member States to help promote the development of wave energy. Based on experience at test centres, developers may then proceed to larger scale developments outside test centres and begin to comply with the applicable consenting process.

Significant wave energy deployments in Europe to date are shown in Table 2. This illustrates the burgeoning state of the wave energy industry. There have been no commercial scale wave energy farms installed apart from the interrupted deployment of three Pelamis devices in Portugal in 2008. 
Table 2

Summary table of wave energy developments to date (August 2013).

\begin{tabular}{|c|c|}
\hline Country & Significant wave energy deployments to date (August 2013) \\
\hline Denmark & $\begin{array}{l}\text { - Various testing and demonstrations of different devices at Nessum Bredning test centre: } \\
\text { o Wave Dragon }(20 \mathrm{~kW}): 2003-2006 \\
\text { o Wave Star }(1.8 \mathrm{~kW}): 2006-2009 \\
\text { o Dexawave: } 2008 \\
\text { - Various testing and demonstrations of different devices at DanWEC test centre: } \\
\text { o Wave Star }(110 \mathrm{~kW}): 2009 \text {-present } \\
\text { o Dexawave }(5 \mathrm{~kW}): 2011 \text {-present }\end{array}$ \\
\hline France & - No deployments to date \\
\hline Ireland & $\begin{array}{l}\text { - A number of short term deployments of } 1 / 4 \text { scale Wave Bob and Ocean Energy Buoy devices, } \\
\text { both }<20 \mathrm{~kW} \text {, at the non-grid connected Galway Bay Test Site between } 2006 \text { and } 2011\end{array}$ \\
\hline Portugal & $\begin{array}{l}\text { - PICO Power Plant }(500 \mathrm{~kW}) \text {, grid connected and used for testing and demonstration since } 1999 \\
\text { - Pelamis Aguçadoura Wave Farm }(3 \times 750 \mathrm{~kW}) \text {, grid connected for } 3 \text { months, } 2008 \\
\text { - Various testing of small and full scale WaveRoller devices at Peniche Test Site }\end{array}$ \\
\hline Spain & $\begin{array}{l}\text { - Mutriku Breakwater Wave Plant (<300 kW), demonstration project operational and grid con- } \\
\text { nected since } 2011 \\
\text { - Medium scale testing of Ocean Power Technologies PB40 (40 kW) during } 2008\end{array}$ \\
\hline Sweden & $\begin{array}{l}\text { - Testing and demonstration of small number of Sea based WECs (10 kW each) at grid connected } \\
\text { Lysekil Test Centre since } 2006\end{array}$ \\
\hline United Kingdom & $\begin{array}{l}\text { - Testing of various full scale WECs at grid connected European Marine Energy Centre (EMEC) } \\
\text { since 2004: } \\
\text { o Pelamis P1 }(750 \mathrm{~kW}): 2004-2007 \\
\text { o P2 }(2 \times 750 \mathrm{~kW}): 2010 \text {-present and 2012-present } \\
\text { o Aquamarine Power Oyster } 1(315 \mathrm{~kW}): 2009-2011 \\
\text { o Oyster } 800(800 \mathrm{~kW}): 2012-2013 \\
\text { o Wello Penguin }(500 \mathrm{~kW}): 2012 \\
\text { - Limpet OWC }(500 \mathrm{~kW}) \text {, Islay, Scotland, grid connected 2000-2013 } \\
\text { - Fred Olsen BOLT Lifesaver ( } 240 \mathrm{~kW}) \text {, deployed at sheltered, non-grid connected FabTest test cen- } \\
\text { tre, } 2012-\text { present } \\
\text { - The WaveHub Test Centre was fully commissioned in } 2012 \text { and a number of developers (e.g. Car- } \\
\text { negie, Fortum, Seatricity and Simply Blue Energy) intend testing devices at the facility in future }\end{array}$ \\
\hline
\end{tabular}

There are many different generic types of device being deployed (onshore, nearshore, offshore, floating, bottom mounted, etc.) No single device or generic type has been proven superior to others and it is likely that different types will suit the various deployment zones that can be exploited (e.g. shoreline, $15-25 \mathrm{~m}$ water depth, $>25 \mathrm{~m}$ water depth, etc.). In terms of achieving ocean energy targets, there are currently $10 \mathrm{MW}$ of installed wave and tidal stream capacity in the EU, almost a threefold increase since 2010 [21]. This figure is, however, substantially less than what was predicted in Member State NREAPs but it is important to stress that this is not unique to ocean energy: the European Commission, in its second progress report on the implementation of the Renewable Energy Directive (2009/28/EC), has stated that generally there was a "solid initial start at EU level but with slower than expected removal of key barriers to renewable energy growth, with additional efforts by particular Member States being necessary" [24]. The progress report emphasises that, at EU and Member State level, "further efforts are needed in terms of administrative simplification and clarity of planning and permitting procedures and for infrastructure development and operation" though this is not unique to ocean energy.

\section{Methodology}

Focussed workshops and questionnaires were conducted with wave energy test centre developers and wave and tidal device developers across Europe so as to capture the experiences gained to date in the consenting of wave energy deployments and project developments. The rationale being that lessons could be derived from these experiences which in turn could inform the development of recommendations on how processes and procedures could be improved. The workshops were organised in such a way as to engage different stakeholder groups and document their experiences, 
make recommendations and assist in achieving the project objectives. Detailed information on the each workshop is available in the associated project reports [25-28].

\subsection{Workshops}

The first workshop [25] aimed to gather up-to-date information on wave energy test centres and independent developments from those involved in them, discuss the current situation, identify possible solutions and where efforts should be focused. Participants included representatives from EMEC in Orkney (Scotland), Wave Hub in Cornwall (England), BIMEP in the Basque Country (Spain), Lysekil (Sweden), Ocean Plug/Pilot Zone (Portugal), the PLOCAN Platform in the Canaries (Spain), SEM-REV Test Centre in France and the 'Waveroller' device developer from Finland. By addressing these objectives the workshop provided an important benchmark for current barriers to development of the sector and potential solutions based on the reality of practical experiences. Group discussions took place in the form of break-out groups organised so that each table had people from a range of marine sectors and backgrounds.

A subsequent workshop [27] was targeted specifically at regulators. The objectives were not only to facilitate information exchange on regulatory processes but to explore the requirements of different EU law and policy requirements and examine new and innovative management approaches to promote the sustainable development of the wave energy industry. Participants shared their perspectives on consenting processes for wave energy in their country covering the UK (as a whole), Scotland (which has certain independent consenting powers), Sweden, Spain, Ireland, Portugal with audience contributions representing the USA, New Zealand, Taiwan and Australia. Each speaker was asked to address three questions: how consenting was currently conducted, how they would like to see it done in future with larger scale projects in mind, and finally to identify what they believed to be the key barriers to improving consenting processes. Breakout sessions focused on adaptive and risk-based management approaches.

\subsection{Questionnaires}

Further insight into both operational and planned ocean energy developments was gained through the completion of a questionnaire, designed and circulated to wave energy test centre developers and wave and tidal device developers [29]. The questionnaire consisted of nine qualitative questions relating to regulatory procedures, how stakeholders were engaged in the process and how their concerns were managed. The survey aimed to capture the experiences of both the formal regulatory process, such as EIA which has public consultation as a requirement, but also more informal mechanisms, such as awareness campaigns and media coverage. Responses were obtained from all test centres and accordingly should provide a very accurate portrayal of the consenting processes and public participation as they operated at that time.

\section{Results}

This section summarises the key findings from both the workshops and the questionnaires, subdivided into the key thematic areas.

\subsection{Regulatory and consenting processes}

A comparison of different elements of the consenting processes for ocean energy across the partner countries is presented in Table 3. In general participants and respondents were of the opinion that legislation was fit-for-purpose. There appears to be widespread variation in the interpretation and application of the Environmental Impact Assessment Directive and Habitats Directive requirements across the EU. This can have direct impacts on the operation of national consenting processes. On a positive note, questionnaire respondents attributed many of these barriers to the current status of wave energy and added that the situation would change as familiarity with these types of developments increases. 
Comparative table of the consenting process for ocean energy test centres.

\begin{tabular}{|c|c|c|c|c|c|}
\hline Country & Licensing authorities & $\begin{array}{l}\text { Dedicated } \\
\text { consenting }\end{array}$ & Stakeholders for statutory consultation & $\begin{array}{l}\text { Mandatory } \\
\text { EIA }\end{array}$ & $\begin{array}{l}\text { Time taken for } \\
\text { consent }\end{array}$ \\
\hline France & $\begin{array}{l}\text { Ministry of Energy, regional prefecture and grid } \\
\text { operator (ERDF) }\end{array}$ & No & 28 (in the case of SEM-REV) & Yes & 14 months \\
\hline Ireland & $\begin{array}{l}\text { Department of Environment; Commission for Energy } \\
\text { Regulation, Local Authority and potentially others }\end{array}$ & No & Numerous: varies according to location & No & $\begin{array}{l}\text { No defined } \\
\text { timeframe }\end{array}$ \\
\hline Portugal & $\begin{array}{l}\text { APA (ARH) } \\
\text { CCDR } \\
\text { DGEG } \\
\text { Municipal council }\end{array}$ & Yes & $\begin{array}{l}\text { Generally a large number; depending on } \\
\text { project characteristics and location }\end{array}$ & No & 1.5 years $^{*}$ \\
\hline Spain & $\begin{array}{l}\text { OMTPD } \\
\text { Ministries of Environment and Industry } \\
\text { Port authority }\end{array}$ & No & 36 entities (in the case of bimep) & Yes & 4 years \\
\hline Sweden & $\begin{array}{l}\text { Regional authorities ( } 24 \text { departments exist in the } \\
\text { country) }\end{array}$ & No & $\begin{array}{l}\text { Generally a large number; depending on } \\
\text { project characteristics and location }\end{array}$ & Yes & $2-9$ years \\
\hline United Kingdom & $\begin{array}{l}\text { A one-stop shop is operational in Scotland (Marine } \\
\text { Scotland); } \\
\text { MMO in England and Wales; } \\
\text { DOENI, DETINI and DOE Planning in Northern Ireland }\end{array}$ & $\begin{array}{l}\text { To date, only } \\
\text { operational for } \\
\text { Scotland }\end{array}$ & $\begin{array}{l}\text { Numerous: varies according to each } \\
\text { jurisdiction }\end{array}$ & Yes & $\begin{array}{l}9 \text { months }{ }^{*} \text { in } \\
\text { Scotland } \\
15 \text { months in } \\
\text { England and } \\
\text { Wales } \\
\text { Not yet defined } \\
\text { in NI }\end{array}$ \\
\hline
\end{tabular}

* The timeframe does not include time taken to compile EIA baseline studies. 
All participants and respondents noted that there are further opportunities to streamline the existing applicable processes. It was viewed that streamlining would make the process more user-friendly and predictable, particularly in terms of the applicable timelines. Ocean energy projects are inherently complicated to consent because they are novel and affect a spatial area that hosts a range of habitats and communities as well as activities such as navigation, fishing, defence and recreational use. The multitude of issues and parties directly or indirectly involved translate into a requirement for more than one consent/permit/licence from more than one authority in the majority of countries examined. Often this creates ambiguity for those trying to navigate the process, adding delay and expense to developers. Cable-laying and grid infrastructure associated with wave energy device deployments are usually subject to a separate and independent consenting process (France, Ireland, Portugal, Spain and the UK). Certain test centres and demonstration sites (Galway Bay, Ireland; FaB site, England and Ocean Plug, Portugal) are not grid-connected preferring to operate initially with no connection and focus on device behaviour and survivability. If required, these can be grid connected at a later date. Wave energy projects that necessitate the construction of associated onshore works tend to be consented under the normal terrestrial planning process.

The "one-stop-shop" approach to administering consents, whereby a single point of contact performing a range of services is available, was regarded as successful by those who had utilised it; primarily those in Sweden and the UK. In Sweden the first applicable consenting process took almost nine years to complete but once better coordination, in the form of the one-stop-shop, was initiated the time taken to consent a project was reduced to approximately two years, depending on the level of environmental studies required. Marine Scotland adopted the one-stop-shop approach so as to provide a single contact for advice, enquiries and applications to simplify consenting and reduce the burden on applicants, regulators and other parties. The system in Scotland is also intended to facilitate coordinated consultation with nature conservation bodies and other parties so as to promote interaction and more holistic assessment of proposed projects reducing the chances of duplication of effort. Developers expressed the opinion that this model of administration should be implemented elsewhere. It was opined that employing this approach would also help ensure consistency between the various requirements (licensing, monitoring, etc.) across regulatory authorities as well as other maritime industries. Regulators who participated in the workshops explained that the decisions they make must be based on evidence which underpins their advice and consequently enables them to defend the decision. Certainty is difficult when ocean energy technology is largely new with limited 'evidence' available on their environmental effects particularly for larger scale arrays and future farms. This can be frustrating for all parties. Regulators expressed the view that in certain cases there is a need for developers to accept that processes, staff and requirements could all change during the course of a particular development. In the current economic climate, it was also put forward that the resources of many Government departments and competent authorities are limited which can have implications for the speed and efficiency at which applications are processed.

Developers asserted that regulators needed to be clearer on what they required from developers as early as possible, preferably from the outset of the planning process. Some regulators were of the opinion that there was a limited understanding of the complexity of consenting processes by some applicants. This culminated in a majority view that more guidance on navigating the process was essential. This would have the effect of improving understanding and compliance whilst also potentially having a positive impact on timelines associated with consenting. Many developers believed that early engagement with regulators played a key role in obtaining a successful consenting outcome. Preapplication consultations are mandatory in some EU countries, for example in the UK and Ireland. Participants at the workshops viewed this as crucial to anticipating and addressing potential issues and also avoiding costly and time consuming problems. During these discussions the concept of design flexibility is often addressed, whereby minor changes in project design are normally acceptable but if the developer requires major changes in the project, additional assessments, and perhaps new consents, will be needed. Developers tend to view the lack of flexibility in the consenting process as frustrating. They stated that at the initial consenting stage full knowledge of technology design, device types and numbers or supply chain arrangements may not be fully known and that devices may also evolve during the consenting process. Conversely, regulators are required to apply the pertinent 
legislation and consequently must ensure, for instance, that a project will have no significant environmental impacts which may result if there is substantial deviation from the original project design.

The majority of participants recognised the potential future role for Maritime Spatial Planning (MSP) in enabling coordinated marine decision-making, providing clarity and transparency to consenting systems, reconciling conflicting sea uses, protecting the environment and encouraging investment. MSP was construed as a tool that prescribed where activities could be located and when these could occur. There was an element of apprehension over how the requirements of ocean energy would be reflected in MSP systems with the dominant view being that MSP was more suited to existing activities rather than future uses. Several workshop participants expect that implementation of MSP will allow more environmental information to be made available from competent authorities. As a new approach to management, it was also hoped that MSP would be both flexible and adaptive thereby enabling more projects to come to fruition. Wider participation in the planning process might also alleviate conflicts of use and concerns over co-location of activities. Workshop participants were also of the opinion that MSP could facilitate better connections between the various forms of environmental assessments (EIA, SEA and AA) and in that way avoid any duplication of effort, which can sometimes be experienced when there are multiple consenting authorities responsible for the same spatial area.

\subsection{Environmental considerations}

Throughout the workshops it was difficult to separate discussions on consenting from EIA, the latter being fundamentally linked to the former in the majority of Member States. Participants viewed a formal scoping exercise as part of the EIA as critical to project planning as it helped to focus developers on the content and topics they need to include in their EIA documentation. By front-loading the process, the likelihood of consent being granted was maximised. There is widespread variation in the application and execution of EIAs across the EU. In Sweden, for example, all ocean energy projects are classified as "environmentally harmful activities" and, thus, require an EIA. In Portugal, as the original transposing EIA legislation did not explicitly include marine renewable energy, a decision was made to include it in subsequent legislation [30]. This stipulates that an EIA is required only if a deployment is within a Natura 2000 site, a national Ecological Reserve or Protected Area and if the regional licensing authority is in agreement. Elsewhere competent authorities take a more traditional approach and decide whether an EIA is required on the basis of size, nature and location of the development [30].

The inconsistencies in application of the EIA process across the EU can result in a degree of frustration to developers who, ideally, would like to be able to utilise results they had obtained previously at other sites and also to budget more accurately for future project costs. As habitats and communities vary according to location this is not always fully possible, however, in recognising the limitations variability can pose, it was suggested that greater efforts could be made by all parties, from all maritime sectors, to share environmental data and information. Opinion was divided in relation to this with some developers expressing the view that there could be issues surrounding intellectual property (IP) rights and commercial sensitivities. Usually developers subsume the costs relating to surveys and data collection associated with EIA, hence conferring data 'ownership' rights. Conversely other participants, including a limited number of developers, were of the impression that sharing EIA data did not impact upon developer IP and should be treated in a similar way to Health \& Safety which is regarded as being beneficial for the entire sector. It was suggested that sharing of data could be realised if there was a "split-cost model" between developers and the State for the collection of baseline environmental data. A centralised data repository could subsequently be utilised to make the data perpetually available to anyone with a need for it.

As ocean energy is at the pre-commercial stage, almost all device deployments to date have been demonstration-type deployments usually for set, short periods of time. Despite this, the environmental studies required by regulators can be comprehensive. It was widely expressed by developers, and some regulators, that the obligations placed on proponents of small scale developments should be less than those for large scale developments that have potentially more significant environmental effects. Certain developers felt that, on occasion, regulators were not sufficiently precise in their requirements 
for environmental studies. In Spain, for example, the project proponent was required "to monitor noise" as a condition of consent but duration, frequency and methodology for monitoring was not stipulated making it difficult for the developer to comply. Regulators explained that not every element of the marine environment is fully understood and that ocean energy devices are new, introducing higher uncertainty which can result in seemingly onerous environmental monitoring. There are also uncertainties in monitoring methodology, equipment utilised and parameters considered.

Workshop participants were of the opinion that this situation would change as more devices are deployed and all parties became more familiar with device operation and impacts. In the shortterm, however, developers tend to be small or medium sized enterprises with limited resources and consequently years of environmental monitoring has the potential to put considerable strain on those enterprises. To address this issue, participants advocated early engagement with regulators at the pre-consent stage as well as with other stakeholders. Regulators stated that there was a need for hypothesis testing at selected sites where particular sensitivities had been identified that could be extrapolated to other projects. They also noted that studies should prioritise the matters of most uncertainty, both ecological and socio-economic. Many of the developers present, for example MCT and Aquamarine Power, acknowledged that the challenge ahead is to work in a collaborative manner so as to initiate procedures that are environmentally acceptable and economically viable.

\subsection{Stakeholder engagement and issues raised}

Public participation is an essential and obligatory part of the EIA process. Directive 2003/35/EC amended the parent EIA Directive and provides for public participation in respect of the drawing up of certain plans and programmes and in that way align the provisions on public participation with the Aarhus Convention. In practical terms this means that consenting authorities must consult with statutory environmental authorities, other interested parties and the public on documentation associated with the EIA process. Consenting authorities must inform the public where the information can be viewed; if data can be obtained and from where; the timeframes for commenting on the documentation and to whom these should be submitted; and the nature of the decision(s). Statutory consultees will be contacted by the consenting authority. In contrast, it is up to the individual to engage actively in the EIA process, once information on where the documents are available has been advertised. The results of consultation and information gathered must be taken into consideration in the consenting process. The final decision made by the consenting authority must be made known to the public. This should include the content of the decision, any conditions attached to the consent, the basis (reasons) for the decision and a description of the main measures to avoid, reduce and, if possible, offset the major adverse environmental effects. All of these considerations constitute the formal approach to stakeholder engagement.

Project developers often take informal approaches to stakeholder engagement particularly where there are perceived problematic issues or potential 'showstoppers'. Developer-led approaches tend to consist of public meetings and open days, media campaigns and interviews as well as dedicated meetings with key stakeholders that will be directly impacted upon by the project in question. Workshop participants and questionnaire respondents confirm that stakeholder engagement is an essential part of the consenting process. In France and Northern Ireland dedicated advisory committees were formed so as to follow the project's development and consenting and to advise on certain specific aspects such as fisheries and environmental impacts. At EMEC in Orkney (Scotland), each time a new developer agrees to deploy a device at one of its test berths, the relevant stakeholders are consulted. Given the levels of activity in Orkney, this has led to certain stakeholders being overloaded, an issue which is now being addressed at Government level [29]. In certain locations, efforts to engage stakeholders had to be deferred until further decisions had been made about the project and its development schedule. This was the case at Ocean Plug in Portugal where decisions on the location of cables and the sub-station had yet to be made. Despite this those involved in delivering the project were developing a stakeholder and public outreach plan which involved the local authority and reflected the area's socio-economic characteristics.

Elsewhere across Europe, informal and frequent discussions were the mainstay of the engagement process and enabled all parties to be involved to the degree they themselves wished. One key factor in 
influencing the approach taken to stakeholder engagement at existing wave energy sites, is the anticipated level of overlap with other maritime activities. This focused predominantly on those involved in fisheries, recreation and navigation. In the Basque Country, the EIA conducted for the Biscay Marine Energy Platform (bimep) identified that there would be impacts on traditional fisheries operated by small-scale family-owned vessels. Accordingly, it became necessary for the project developer to meet directly with the Armintza Fishermeńs Guild in an endeavour to agree on the impacts bimep would have on their economic activity and possible mitigation measures including compensation. Given the advanced stage of the development planning process, the members of the Association were of the opinion that objecting to the development would serve no purpose hence the only recourse open to them was to negotiate compensation. Compensation took the form of a direct monetary payment to those affected (through their industry association) or alternative livelihood options. The latter included the possibility to use their vessels in associated site and survey works or to re-train as personnel who could conduct operation and maintenance at the site in future. In Cornwall (UK) at the Wave Hub site, a strategic mitigation phase looked specifically at the potential impacts of Wave Hub on the fishing community. As a result Wave Hub created a monetary fund for the development of fishing activities in the Cornish north coast.

At the test centres studied, as well as at other wave energy development sites in Denmark, Norway, Scotland, potential impacts on commercial fisheries was the most cited stakeholder concern. At the Atlantic Marine Energy Test Site (AMETS) in Ireland these concerns were addressed through a proactive consultation process with the fishermen, culminating in a re-design of the outer test area to facilitate crab-potting and minimise impact. Members of the public along with eNGOs expressed concerns about the environmental impacts of devices on the marine environment and with respect to certain species in Portugal, Scotland, Spain and Sweden. Generally these were addressed through further explanation of the project and operation of the device(s) and in some cases through additional environmental surveys and on-going monitoring. Interference with navigation from both a logistical perspective and also a health and safety one was expressed in both Norway and in England, around the Wave Hub site. Given the Wave Hub's proximity to the busy English Channel this was to be expected. Marking the zone with buoys and lights, where appropriate, as well as proposing a site location away from shipping lanes were the main approaches taken to alleviating such matters. Opinions on the use of safety zones around wave energy devices were mixed. At Wave Hub (England), an extension of the safety zone to the full site necessitated a change to the relevant international standard [31]. Elsewhere stakeholders expressed concern about safety and exclusion zones interfering with established legal rights to fish and navigate. Impacts on recreational surfing activity was identified as a concern in Ireland, Portugal and the UK. As many wave energy developments are still in the final planning stages, and not yet operational, it is difficult to gauge how local concerns will be reconciled.

\subsection{Stakeholder support and knowledge of socio-economic benefits}

Respondents from Denmark, France, Ireland, Norway, Portugal, Spain, Sweden and the UK, representing both test centres and private developments, all expressed experience of unanimous support for their development from public, private and political sectors. Public authorities, such as local town councils, were of the opinion that such developments would bring strong socio-economic benefits to the locality as well as provide an impetus for inward investment into facilities and infrastructure. The private sector were also supportive as they recognised the potential for becoming intrinsic parts of the supply chain to this new industrial sector in future. In Scotland and Sweden respondents opined that the perceived lower visual impact of wave energy developments won favour with the public. From a Portuguese perspective, respondents from the Ocean Plug development conveyed the hope that a proportion of the taxes paid by the developer could be allocated to the local community to improve facilities in addition to providing employment opportunities in a peripheral location. Whilst all developers stated that the socio-economic benefits of their development were highlighted to the local community or region during public events, it would appear that few had actually conducted studies to support claims of these benefits. Only respondents from SEM-REV, France; WestWave in Ireland; WaveRoller in Portugal and both EMEC and Pelamis Wave Power in Scotland had examined socio-economic impacts specifically. Respondents from elsewhere indicated that as current deployments were small 
in scale and sometimes temporary they did not have socio-economic benefits per se but were best viewed as strategic, providing a foundation for enabling and promoting the ocean energy industry.

At the moment both the manufacturing and supply chain elements of a wave energy project are bespoke. This needs to change for the sector to become more financially viable and developers were of the opinion that more of an effort should be made to collaborate with potential suppliers. By doing this, suppliers would have a better understanding of the potential of the sector and consequently would be in a position to adapt and provide a more useful and tailored service. Developers highlighted the need for supply chain companies to work on components that can survive the realities of the harsh maritime environment where wave energy devices will have to function. In this context, many acknowledged that useful lessons can be learned from the experience of other sectors but that an accessible mechanism through which to do this does not yet exist. In relation to data, this needs to be made available at an affordable cost. Whilst everyone consulted was eager to see wave energy progress to commercial scale, there was widespread recognition that several fundamental engineering and technical issues require further research, development and funding. Joint finance and support mechanisms from the public and private sectors were viewed as essential for progress and development and these factors should not be under-estimated. Funding needs to be available to all stages of project development and ideally should match Technology Readiness Levels. A robust risk management framework needs to be formulated by regulatory authorities and applied by developers in receipt of funding support. Developers and regulators both stressed that it is critical that due diligence is carried out on the individual company rather than the entire ocean energy sector.

\section{Discussion}

As evidenced from the preceding sections, a range of factors continue to act as barriers to development of the wave energy sector, according to those who have negotiated the consenting process to date. It is critical to recognise that, for the most part, these 'barriers' will be resolved as the number of developments increase and there is greater familiarity with, and knowledge of, the technology. Similarly it is important to emphasise that certain barriers could be addressed now and doing so could act as an important accelerator to ocean energy development. Several so-called 'barriers' arose repeatedly in the workshops and questionnaire responses. These can be categorised into four thematic areas:

1. Complex planning processes,

2. Administrative procedures,

3. Environmental Impact Assessment process,

4. Interactions with other marine uses and stakeholders.

Recommendations on how each of these can be addressed, based on input from regulators, industry and individual stakeholders, are presented below.

\subsection{Complex planning processes - the need for MSP}

Management of the marine environment and activities therein, is highly sectoral and often fragmented. There is a definite need for more integrated planning whereby the authorities involved have established formal or informal approaches to coordination and communication with each other. Strategic spatial planning is one such approach. This aims to provide a vision, set priorities, dedicate resources and ultimately ensure that all actors are working towards a common goal. In the context of marine renewable energy development, responsibility for strategic spatial planning rests partly with the EU, as the over-arching EU energy policy maker, and partly with national governments, as the national policy maker for planning and development. The EU's Integrated Maritime Policy identifies Maritime Spatial Planning (MSP) as one of the cross sectoral tools essential to its delivery and crucial for legal certainty, predictability and transparency, thereby reducing costs for investors and operators, especially those with working in more than one Member State [32]. MSP is an integrated, participatory and adaptive process that facilitates planning and management of maritime activities, balancing ecological objectives with economic and social ones. As such, it is intended to support rational use of the 
sea by providing a stable and transparent planning system for maritime activities and users [33]. Competency for the design and implementation of MSP resides with individual Member States and not with the EU per se. The EU recently adopted a Directive on Maritime Spatial Planning (2014/89/EU) which requires Member States to formulate Maritime Spatial Plans. Article 6(2) states that these planes must identify all existing human activities and the most effective way of managing them; take interactions between the sea and land into account; establish appropriate cross-border cooperation mechanisms; create means of public participation for stakeholders, authorities and the public concerned; use the best available data and arrange the sharing of information between stakeholders.

The workshops and questionnaires confirm that MSP is regarded as a solution to conflicts of use in the maritime space. There is limited evidence to support such a view given the current varying levels of MSP implementation across Europe. The approach taken to MSP will differ according to the size and nature of the maritime space, the range of activities going on there along with pertinent legal and institutional arrangements. This means that MSP can take different forms in different locations such as zoning specific areas for certain uses or applying regulations to activities. MSP is not a replacement for sectoral planning, rather it seeks agreement between the plans that each sector develops for a given area. MSP is a planning process; the process element being particularly important in the context of wave energy development as it seeks to ensure the necessary participatory aspect, actively involving stakeholders in the design and operation of MSP. Existing environmental assessment information should be used to inform the design of MSP as it must incorporate biodiversity objectives as well as those of industry. In this way it should be possible to build upon existing environmental information and add to the knowledge base thereby avoiding duplication of effort, repeatedly raised as problematic by project developers. It is essential, however, that there is better coherence between strategic level plans and assessments (e.g. MSP and SEA) and operational level assessments (e.g. EIA and Appropriate Assessment).

\subsection{Administrative procedures - the need for coordination}

The frustrations expressed by developers, and some stakeholders, tend to centre on the procedures relating to consenting rather than the actual consent(s) required. The frustration stems from bureaucracy, uncertain timeframes and perceived duplication of effort. One-stop shop and parallel processing approaches were raised recurrently as alternatives to be utilised for streamlining consenting. The term one-stop shop has its genesis in business related disciplines, particularly organisational theory. It seeks to provide a single point of contact or location where a multitude of services are available. The advantage of this is efficient and convenient service, saving time and money. With respect to wave energy, a one-stop shop would incorporate all the consents required for environmental, land and marine-based project elements as well as the project's electrical permits. One-stop shops dealing with ocean energy, or more commonly all marine developments, tend to consider only the marine environmental elements of a project, namely the EIA process and licence of the sea space. This is inherently linked to the institutional structure of the region/country. If all responsibilities relating to energy developments, for example, reside in one government department or authority it should theoretically be much easier to coordinate consenting in a single process. Conversely, where responsibilities are divided between a number of different departments each with their own legal remits it will be much more difficult to coordinate effort and could ultimately require legal amendment and significant financial and resource investment.

Marine Scotland was frequently cited as the epitome of the desired 'one-stop shop' approach with responsibility for marine energy, sea and recreational fisheries, aquaculture, marine planning and licensing. The Marine (Scotland) Act 2010 created a statutory basis for both marine planning and a streamlined licensing system, both of which are the responsibility of Marine Scotland. It takes an integrated approach to marine planning and management so that wider impacts can be taken into account. Having responsibility for strategic policy-making as well as operational decision-making in the form of granting licences also creates a more stable environment for long term business decisions. Marine Scotland has also been proactive in developing guidance for those who use its services and in providing supporting infrastructure. Its comprehensive programme of research relating to the environmental effects of marine renewables has enabled it to base decisions on scientific evidence which 
has resulted in a reduction in the level of information needed from developers for certain lower risk projects, contained in its Survey Deploy and Monitor policy. Whilst Marine Scotland was established as a result of new legislation, this can be contrasted with the situation in Denmark where the national Danish Energy Agency (DEA) operates as a 'one-stop shop' for the project developer in relation to the many, often opposing, interests connected to use of the sea. Importantly, the operation of this approach did not require the creation of a new agency but rather more formalised channels for communication between the various regulatory authorities involved; a model that could be rolled-out in other jurisdictions [34]. Before granting a licence to establish a marine renewable energy development the DEA conducts a hearing with other regulatory authorities and relevant local municipalities to elucidate any concerns surrounding development of the project.

Responses from the south of Europe tended to favour a parallel processing approach to consenting. In Spain, for example, developers submit their application to one central authority, the Department of Industry, who then passes the application on to the other regulatory authorities for comment. Each authority returns their comments on the application to the central body (the Department of Industry) who then decides whether to proceed with granting consent or to ask for additional work. One of the main drawbacks of this system is that often the authorities' procedures are sequential and applicants are required to obtain one licence before being able to apply for the next one. Consequently, a delay in one licence will result in a delay to all subsequent licences. The hypothesis of the parallel processing approach is that one step in project planning should not depend on successful completion of an earlier step; rather procedures should occur in parallel. Such a system appeals to developers as they feel they can monitor the progress of their application more closely and understand clearly what needs to be provided to whom and when. Whilst applications for development consents may be processed simultaneously to expedite total review and processing time for a project, there will always be interdependence between the required consents. The idea of having one central authority to consider all the submissions and concerns of other regulatory authorities appears sensible, providing they have the expertise to act as an arbiter on the comments returned. If authorities agreed in principle to the development, perhaps by way of an administrative sanction, this may avoid spending further time on a planned project that is inappropriate.

\subsection{Environmental Impact Assessment Process - the need for clearer requirements}

Criticisms of the EIA process covered a myriad of factors ranging from procedural aspects to broader implications such as monitoring requirements. Under the EIA Directive, wave energy developments are not included in Annex I hence an EIA is not mandatory. Usually wave energy developments are subject to an EIA as they qualify as "industrial installations for the production of electricity", specified in Annex II, 3(a) of the Directive. Certain EU Member States take a very literal interpretation of this, subjecting all wave energy developments to EIA. Other countries suggest that, as wave energy is not specifically listed in the Annex, they are not subject to the EIA process. The European Court of Justice (ECJ) has however already shown that the Directive has a wide scope and broad purpose and consequently it must not be assumed that a project is excluded simply because it is not expressly mentioned in either the Directive or associated regulations [35-37]. Results from this work indicated that in most EU Member States wave energy projects are "screened" for EIA because of their unknown or uncertain environmental effects rather than the scale of the development.

The EC has already acknowledged that the screening mechanism should be simplified and clarified, for example, by detailing the selection criteria listed in Annex III and by establishing Community thresholds, criteria or triggers [38]. Where smaller projects have potentially less significant impacts but still require assessment, simplified procedures should be considered. Examples of this approach are evident from Germany, where the competent authorities have a greater level of discretion over procedures particularly in relation to consultation. This is also the case in France through their 'notice d'impacts' statement and in Portugal where there is an environmental appraisal. A proposal for an amended EIA Directive [39] was published in October 2012 and following significant amendments a revised Directive entered into force on 15 May 2014 (2014/52/EU). Timeframes have been introduced for the different stages of the EIA process: screening decisions should be taken within 90 days (although extensions are possible) and public consultations should last at least 30 days. Another 
important change applies in situations where projects have significant adverse effects on the environment, developers are now obliged to avoid, prevent or reduce such effects and projects will be monitored using procedures determined by the Member States.

Completion of an EIA usually informs the monitoring requirements attached as terms and conditions to the development consent. The EIA Directive itself does not impose a monitoring requirement though this will change with the entry into force of the revised version (2014/52/EU). It is the outcome of the EIA process that can dictate a need for monitoring in the view of the competent authority. The limited amount of scientific evidence on potential environmental impacts of wave energy due to the nascent state of the sector has been identified as the main cause of this barrier. Given this status, those developers involved in site development are usually less well-resourced than developers likely to be involved in commercial scale projects (e.g. large utility companies). Thus the EIA process can place a large strain on the limited human and financial resources of the former. This raises the question of data sharing and management. To reduce the burden on small developers in the short term, who will mostly be deploying single or small numbers of devices, it has been suggested that test centres play a more significant role in gathering and sharing environmental monitoring data across the industry and EU Member States. Many test centres have recognised their responsibility in this regard and consequently have established research programmes that aim to contribute towards the standardisation of methods for measuring environmental effects of wave energy deployments. Examples of this include acoustic monitoring research projects at EMEC in Scotland [40], in Galway Bay in Ireland [41] and Wave Hub [42] in England, that seeks to contribute to the standardisation of methods for measuring underwater noise. Developers were of the opinion that there is not enough guidance from regulators on the scope of EIAs and that the subsequent specified monitoring requirements are too vague. It was also stated that there is a lack of flexibility when it comes to project design in the consenting process and widespread support for an adaptive management approach.

\subsection{Interactions with other marine projects and stakeholders - the need for early participation}

Consultation with stakeholder groups regarding wave energy developments was generally regarded positively by developers; nevertheless, it has also been identified as a possible barrier to the development of wave energy by some developers. To date device deployments have been at wave energy test centres, where the operators of the test centre undertake much of the stakeholder consultation process as part of their hosting arrangements. For the majority of these deployments, formal statutory and sometimes informal consultations have been undertaken. Experience from these deployments suggests that, for the most part, developers have been satisfied with the consultation process. The process is, however, both resource and time consuming. For projects receiving large amounts of public funding, (e.g. wave energy test centres) and future commercial wave farm developments this may not be a problem. For the current status of the sector, this presents a problem for smaller developers who, by definition, are less well resourced. There is a fear that investors could be put off by perceived delays caused by the stakeholder consultation process. Awareness raising and communicating with stakeholders from project inception to operation and monitoring is critical for fostering understanding and support both among the public and among regulatory agencies. The information put forward at consultation events needs to be credible and evidence based and presented in an accessible and understandable format. Experience from test centres and deployments to date demonstrate the importance of engaging with stakeholders early so as to mitigate potential issues as effectively as possible. Guidance documents to advise regulators, developers and stakeholders on siting of developments, how to participate in the consenting process and how to engage effectively with developers is also important for addressing this barrier.

\section{Conclusions}

This paper has documented the experiences of those who have been actively involved in the planning and consenting of wave energy projects in wave energy test centres and other project sites across the European Union. Active engagement with wave energy device and project developers, regulatory 
authorities, stakeholders, environmental consultants and others was achieved through dedicated workshops and findings supplemented by questionnaire surveys. The views and opinions documented in this paper provide an accurate portrayal of the consenting systems in place as they have been experienced and consequently it represents an informed depiction of the factors that have the potential to positively and/or negatively affect the progression of ocean energy as a developing industrial sector, as well as achievement of the EU's renewable energy targets. It is essential to highlight that only a relatively small amount of wave energy capacity, in comparison to ocean energy targets for Member States, has been installed. This implies that the consenting process for wave energy developments in Member States has not yet been seriously tested. Installed capacity has largely been single devices deployed at specially built wave energy test centres, and demonstration projects, in different Member States.

There is a possibility that some of the barriers identified will diminish as the sector expands, though it could be more judicious to assume that some of the barriers discussed will become more serious as the size of developments increase. This work therefore provides an important baseline on what is currently viewed as problematic and/or enabling. Addressing the number of consents required and reducing the number of authorities involved remains a challenge along with consistency in the application of EIA to wave energy developments. Marine Scotland are at the vanguard of consenting processes for marine renewables, with its approach and accomplishments heralded across Europe. Its success can be attributed to multiple factors: an innovative legislative framework that led to the creation of Marine Scotland, a political environment that is fully supportive of marine renewables and willing to invest in research and development related to it and, perhaps most tellingly, a realisation that consenting processes were not as efficient or effective as they could be leading to actual changes in procedures and processes. Whilst not every country may have all these enabling conditions in their country at this time, it is clear from experiences to date that relatively simple actions, such as having an allocated contact point or providing guidance to developers, can have a major influence on how the consenting process is perceived amongst those trying to work within it. Encouragement can also be drawn from the obvious desire of developers, regulators and stakeholders to collaborate more in order to progress the sector. Likewise the experiences of the offshore wind sector demonstrates that large scale developments can gain consent. Whilst progress of wave energy remains frustratingly slow in the minds of some, the potential of the wave energy sector remains huge with the number of deployments continuing to grow across Europe.

\section{Acknowledgements}

This study was carried out as part of the SOWFIA Project (www.sowfia.eu), Grant Agreement number: IEE/09/809/SI2.558291, funded by Intelligent Energy Europe. The sole responsibility for the content of this publication lies with the authors. It does not necessarily reflect the opinion of the European Union. Neither the EACI nor the European Commission is responsible for any use that may be made of the information contained therein. Anne Marie O'Hagan's contribution is supported by Science Foundation Ireland (SFI) under the Charles Parsons Award for Ocean Energy Research (Grant number 06/CP/E003) in collaboration with Marine Renewable Energy Ireland (MaREI), the SFI Centre for Marine Renewable Energy Research (12/RC/2305).

\section{References}

[1] European Ocean Energy Association, Industry Vision Paper 2013, EOEA, Brussels, 2013. <http://www.oceanenergy-europe. eu/images/Publications/European_Ocean_Energy-Industry_Vision_Paper_2013.pdf/>.

[2] WAVEPLAM, Non-technical barriers to wave energy implementation, Report from the WAVEPLAM project, authored by Frank Neumann, WavEC, Portugal, 2009.

[3] EquiMar, Equitable Testing and Evaluation of Marine Energy Extraction Devices in terms of Performance, Cost and Environmental Impact - Work Package 6 report on Environmental Impacts, 2011. <http://www.equimar.org/equimarproject-deliverables.html/>.

[4] ORECCA, Environment, Regulation and Legislation, A report by David K. Woolf, Environmental Research Institute, University of the Highlands and Islands - North Highland College (ERI, UHI - NHC) contributing to Work Package 2 of the ORECCA project, 2011. <http://www.orecca.eu/c/document_library/get_file?uuid=da905529-e66c-4a3f-92da4af2e19d5a4d\&groupId=10129/>. 
[5] D. Greaves, C. Perez Collazo, D. Magagna, D. Conley, I. Bailey, T. Simas, B. Holmes, A.M. O’Hagan, J. O'Callaghan, Y. TorreEnciso, D. Marina, C. Huertas Olivares, I. Le Crom, J.B. Saulnier, J. Sundberg, C. Embling, M. Witt, B. Godley, J. Chambel Leitão, SOWFIA Project Report: Enabling Wave Power: Streamlining processes for progress, 2013. <http://www.sowfia. eu/fileadmin/sowfia_docs/documents/Final_publishable_report_Final.web_version.EN.pdf/>.

[6] Sustainable Energy Ireland and Marine Institute, Ocean Energy in Ireland. Submitted to the Department of Communications, Marine \& Natural Resources. Sustainable Energy Ireland and Marine Institute, Dublin, 2006. <http:// www.seai.ie/Renewables/Ocean_Energy/Ocean_Energy_Strategy/Ocean_Energy_Strategy_Report_18082006.pdf/>.

[7] Federal-Regional Energy Consultation Group CONCERE-ENOVER, National renewable energy action plan for Belgium pursuant to Directive 2009/28/EC, 2010. <http://ec.europa.eu/energy/renewables/transparency_platform/action_plan_en. $\mathrm{htm} />$.

[8] Klima Og Energiministeriet, National Action Plan For renewable energy in Denmark, 2010. <http://ec.europa.eu/energy/ renewables/transparency_platform/action_plan_en.htm/>.

[9] Ministère de l'Écologie, de l'Énergie, du Développement durable et de la Mer, National action plan for the promotion of renewable energies 2009-2020, 2009. <http://ec.europa.eu/energy/renewables/transparency_platform/action_plan_en. $\mathrm{htm} />$.

[10] Federal Republic of Germany, National Renewable Energy Action Plan in accordance with Directive 2009/28/EC on the promotion of the use of energy from renewable sources, 2010. <http://ec.europa.eu/energy/renewables/transparency platform/action_plan_en.htm/>.

[11] Ministry of Environment, Energy and Climate Change (Greece), National Renewable Energy Action Plan in the scope of Directive 2009/28/EC, 2010. <http://ec.europa.eu/energy/renewables/transparency_platform/action_plan_en.htm/>.

[12] Government of Ireland, National Renewable Energy Action Plan - IRELAND, Submitted under Article 4 of Directive 2009/ 28/EC, 2010. <http://ec.europa.eu/energy/renewables/transparency_platform/action_plan_en.htm/>.

[13] Italian Ministry of Economic Development, Italian National Renewable Energy Action Plan in line with the provisions of Directive 2009/28/EC and Commission Decision of 30 June 2009, 2010. <http://ec.europa.eu/energy/renewables/ transparency_platform/action_plan_en.htm/>.

[14] Governo de Portugal, National Renewable Energy Action Plan, submitted under Article 4 of Directive 2009/28/EC, 2010. <http://ec.europa.eu/energy/renewables/transparency_platform/action_plan_en.htm/>.

[15] Ministerio de Industria, Turismo y Comercio, Plan de Acción Nacional de Energías Renovables de España (PANER) 20112020, Government of Spain, Madrid, 2010. <http://www.idae.es/index.php/mod.documentos/mem.descarga?file=/ documentos_20100630_PANER_Espana_version_final_[1]_cdb842de.pdf/>.

[16] Regeringskansliet, The Swedish National Action Plan for the promotion of the use of renewable energy in accordance with Directive 2009/28/EC and the Commission Decision of 30.06.2009, 2010. <http://ec.europa.eu/energy/renewables/ transparency_platform/action_plan_en.htm/>.

[17] Dutch Government, Nationaal actieplan voor energie uit hernieuwbare bronnen (English version), 2010. <http://ec.europa. eu/energy/renewables/transparency_platform/action_plan_en.htm/>.

[18] HM Government, National Renewable Energy Action Plan for the United Kingdom Article 4 of the Renewable Energy Directive 2009/28/EC, 2010. <http://ec.europa.eu/energy/renewables/transparency_platform/action_plan_en.htm/>.

[19] European Renewable Energy Council (EREC), Mapping Renewable Energy Pathways towards 2020: EU Roadmap, EREC, Brussels, 2011. <http://www.repap2020.eu/fileadmin/user_upload/Roadmaps/EREC-roadmap-V4_final.pdf/>.

[20] European Commission, Communication from the Commission to the European Parliament, the Council, the European Economic and Social Committee and the Committee of the Regions, Blue Growth - opportunities for marine and maritime sustainable growth COM(2012) 494, EC, Brussels, 2012. <http://eur-lex.europa.eu/LexUriServ/LexUriServ.do?uri=COM: 2012:0494:FIN:EN:PDF/>.

[21] European Commission, Communication from the Commission to the European Parliament, the Council, the European Economic and Social Committee and the Committee of the Regions. Blue Energy: Action needed to deliver on the potential of ocean energy in European seas and oceans by 2020 and beyond $\operatorname{COM}(2014) 8$ final, EC, Brussels, 2014. <http://eur-lex. europa.eu/legal-content/EN/TXT/?qid=1396419828231\&uri=CELEX:52014DC0008/>.

[22] DG MARE, Ocean Energy: Feedback Statement of the Online Public Consultation held from 14 June to 14 September 2012 , DG Maritime Affairs, EC, Brussels, 2012. <http://ec.europa.eu/dgs/maritimeaffairs_fisheries/consultations/ocean_energy/ index_en.htm/>.

[23] V. Osta Mora-Figueroa, C. Huertas Olivares, B. Holmes, A.M. O'Hagan, Y. Torre Enciso, R.H. Leeney, SOWFIA Project Report: Catalogue of Wave Energy Test Centres (September 2012 update), 2012. <http://sowfia.eu/fileadmin/sowfia_docs/ documents/D2.1_Annex_Update_Sept_2012.pdf/>.

[24] European Commission, Report from the Commission to the European Parliament, the Council, the European Economic and Social Committee and the Committee of the Regions Renewable energy progress report COM(2013) 175 final, EC, Brussels, 2013. <http://eur-lex.europa.eu/legal-content/EN/ALL/?uri=CELEX:52013DC0175/>.

[25] J.A. Domínguez Quiroga, C. Huertas Olivares, D. Magagna, D. Greaves, A.M. O’Hagan, B. Holmes, M. Witt, T. Simas, SOWFIA Project Report: Analysis of Existing Available Data of Wave Energy Experiences (Workshop A), 2011. <http://www.sowfia. eu/fileadmin/sowfia_docs/member_section/D22_Final_Report_U1.pdf/>.

[26] T. Simas, S. Patrício, J. Gonçalves, I. Bailey, D. Magagna, D. Greaves, M. Witt, B. Holmes, A.M. O’Hagan, J. O’Callaghan, J. Sundberg, Y. Torre Enciso, D. Marina, J.B. Saulnier, SOWFIA Project Report: Taking wave energy forward - implementation and community integration (Workshop B), 2012. <http://www.sowfia.eu/fileadmin/sowfia_docs/documents/SOWFIA_ WorshopB_Report.pdf/>.

[27] E. Muñoz Arjona, C. Huertas Olivares, A.M. O’Hagan, B. Holmes, J. O’Callaghan, D. Magagna, D. Greaves, I. Bailey, D. Conley, J. Sundberg, T. Simas, S. Hamawi, J.B. Saulnier, J. Chambel Leitão, C. Embling, D. Marina, SOWFIA Project Report: Navigating the Wave Energy Consenting Procedure - Sharing Knowledge and Implementation of Regulatory Measures (Workshop C), 2012. <http://www.sowfia.eu/fileadmin/sowfia_docs/documents/D.2.5.pdf/>.

[28] T. Simas, I. Machado, S. Hamawi, D. Magagna, I. Bailey, D. Conley, D. Greaves, C. Embling, A.M. O’Hagan, J. O'Callaghan, B. Holmes, J. Sundberg, Y. Torre Enciso, D. Marina, J.B. Saulnier, SOWFIA Project Report: Riding the crest of the wave: 
streamlining approval processes, safeguarding ecosystems (Workshop D), 2013. <http://sowfia.eu/fileadmin/sowfia_docs/ documents/SOWFIA_WorshopD_Report.pdf/>.

[29] E. Muñoz Arjona, C. Huertas Olivares, D. Magagna, D. Greaves, A.M. O’Hagan, B. Holmes, J. Sundberg, T. Simas, S. Patrício, Y. Torre Enciso, D. Marina, J.B. Saulnier, SOWFIA Project Report: Site and technology developers, project financers and authorities questionnaires, 2013. <http://www.sowfia.eu/fileadmin/sowfia_docs/documents/D2.3_Final.Update_feb_2013. $\operatorname{pdf} />$.

[30] Ministério da Economia e da Inovação, Decreto-Lei no. 225/2007 de 31 de Maio. Diário da República, 1.a série No 105, 31 de Maio de 2007, pp. 3630-3638. <https://dre.pt/application/file/638674/>.

[31] International Maritime Organization, Routeing of Ships, Ship Reporting and Related Matters. Amendments to the Traffic Separation Scheme "Off Land's End, Between Longships and Seven Stones", Submitted by the United Kingdom, SubCommittee on Safety of Navigation, 54th session, IMO Doc. NAV 54/3/5 28 March, IMO, London, 2008.

[32] European Commission, Communication from the Commission to the European Parliament, the Council, the European Economic and Social Committee and the Committee of the Regions Maritime Spatial Planning in the EU - Achievements and future development COM (2010) 771, EC, Brussels, 2010. <http://eur-lex.europa.eu/LexUriServ/LexUriServ.do?uri= COM:2010:0771:FIN:EN:PDF/>.

[33] A.M. O'Hagan, Maritime Spatial Planning (MSP) in the European Union and its Application to Marine Renewable Energy, IEA-OES Annual Report, 2011. <http://www.ocean-energysystems.org/ocean_energy/in_depth_articles/msp_in_the_ european_union/>.

[34] A.M. O'Hagan, A review of international consenting regimes for marine renewables: are we moving towards better practice? 4th International Conference on Ocean Energy, Dublin, 2012.

[35] Case C-72/95 Kraaijeveld and Others v. Gedeputeerde Staten van Zuid-Holland [1996] ECR I-05403. <http://eur-lex.europa. eu/legal-content/EN/TXT/?uri=CELEX:61995CJ0072/>.

[36] Case C-435/97 World Wildlife Fund (WWF) and Others v Autonome Provinz Bozen and Others [1999] ECR I-05613. <http:// eur-lex.europa.eu/legal-content/EN/TXT/?uri=CELEX:61997CJ0435/>.

[37] Case C-2/07 Paul Abraham and Others v Région wallonne and Others [2008] ECR I-01197. <http://curia.europa.eu/juris/ liste.jsf?language $=$ en $\&$ num $=c-2 / 07 />$.

[38] European Commission, Report from the Commission to the Council, the European Parliament, the European Economic and Social Committee and the Committee of the Regions on the application and effectiveness of the EIA Directive (Directive 85/ 337/EEC, as amended by Directives 97/11/EC and 2003/35/EC) COM(2009)378 final, EC, Brussels, 2009. <http://eur-lex. europa.eu/LexUriServ/LexUriServ.do?uri=COM:2009:0378:FIN:EN:PDF/>.

[39] European Commission, Proposal for a Directive of the European parliament and of the Council amending Directive 2011/ $92 / \mathrm{EU}$ on the assessment of the effects of certain public and private projects on the environment (COM(2012) 628 final), EC, Brussels, 2012. <http://eur-lex.europa.eu/LexUriServ/LexUriServ.do?uri=COM:2012:0628:FIN:EN:PDF/>.

[40] EMEC, See http://www.emec.org.uk/research/emec-site-specific-projects/> (accessed 28.02.12).

[41] H. Kolar, The Smarts Behind Galway Bay, Information from <http://asmarterplanet.com/blog/2012/09/galway.html, accessed 26/10/2012/>.

[42] M.J. Witt, E.V. Sheehan, S. Bearhop, A.C. Broderick, D.C. Conley, S.P. Cotterell, E. Crow, W.J. Grecian, C. Halsband, D.J. Hodgson, P. Hosegood, R. Inger, P.I. Miller, D.W. Sims, R.C. Thompson, K. Vanstaen, S.C. Votier, M.J. Attrill, B.J. Godley, Assessing wave energy effects on biodiversity: the Wave Hub experience, Philos. Trans. R. Soc. A 370 (1959) (2011) 502529 . 